\title{
Cellular immunity to cartilage link protein in patients with inflammatory arthritis and non-arthritic controls
}

\author{
M C Doran, N J Goodstone, R N Hobbs, B A Ashton
}

\begin{abstract}
Objectives-To determine if increased $T$ cell responses to articular cartilage link protein have any correlation with rheumatoid arthritis (RA), and if $R A$ patients with increased responses to link protein also respond to a 17 amino acid peptide covering the 'arthritogenic' epitope in mycobacterial hsp65 which is homologous with link protein.

Methods-The reactivity of $T$ cells from both peripheral blood and synovial fluid, to highly purified human cartilage link protein, hsp65, the 17 amino acid peptide, and bovine type II collagen was determined in patients with $R A$ and nonarthritic controls, by measuring the rate of mononuclear cell proliferation in the presence and absence of antigen.
\end{abstract}

Results-Using peripheral blood mononuclear cells (PBMC), significant reactivity (stimulation index $(S I)>1.5)$ to link protein was found in 12 of $46 \mathrm{RA}$ patients $(26 \%)$, but in only four of 44 controls (9\%). A greater proportion of RA patients (eight of $17: 47 \%$ ) were reactive to link protein when mononuclear cells from synovial fluid were tested. SI values, however, were generally low $(0 \cdot 5-3 \cdot 1)$ and only one patient showed a PBMC response above a reference range of values calculated from the logarithmic values of the normal control population. No reactivity was observed against a 17 amino acid synthetic peptide including the arthritogenic epitope from the mycobacterial hsp65 to which $T$ cell clones isolated from rats in the adjuvant arthritis model react. However, eight of nine $R A$ patients and all of seven controls reacted to the intact hsp65.

Conclusion-It remains unclear if $T$ cell responses to link protein are involved in the pathogenesis of RA, but it is unlikely that $T$ cells specific for the sequence homologous with the arthritogenic epitope in hsp65 are present in RA patients.

(Ann Rheum Dis 1995; 54: 466-470)

Despite much investigation, the extent to which cellular immune responses within the joints of patients with rheumatoid arthritis (RA) contribute to the pathogenesis of the disease remains unclear. It has been suggested that the most critical mechanism of joint destruction is cytokine secretion by monocytes. ${ }^{1}$ However, a review has presented evidence for the importance of $T$ cells in the immunopathogenesis of RA, and concluded that they were central to the initiation and maintenance of synovitis in RA. ${ }^{2}$

Potential autoantigens under investigation include components of articular cartilage matrix which consists of proteoglycan aggregates within a network of collagen fibrils. ${ }^{3}$ In the proteoglycan aggregate, the binding of aggrecan monomers to hyaluronan is stabilised by link protein. The structure, function, and distribution of link protein and structurally related proteins have been reviewed by Neame et al. ${ }^{4}$ The structure of proteoglycan aggregates changes with aging, and there is a gradual increase in the heterogeneity of proteoglycan monomers. In addition, proteolytic cleavage results in release of glycosaminoglycan (GAG)-rich fragments of aggrecan monomers into the synovial fluid. Proteolysis may result in the release into the synovial fluid of some link protein and the hyaluronan binding region of aggrecan; ${ }^{5}$ these tend to accumulate in the cartilage matrix in association with hyaluronan.

In certain animal models, arthritis can be induced by type II collagen ${ }^{6-10}$ and the less abundant type IX and XI collagens. ${ }^{11}$ Arthritisinas been demonstrated after intraarticular injection of heterologous proteoglycan in rabbits, ${ }^{12}{ }^{13}$ and chondroitin sulphate stripped human fetal cartilage proteoglycan (HFPG) was shown to give rise to polyarthritis and ankylosing spondylitis in female Balb/c mice. ${ }^{14} 15$ In both collagen induced arthritis and proteoglycan induced arthritis, it is possible to induce secondary arthritis by adoptive transfer of cells from immunised donors to naive syngeneic recipients. ${ }^{16}{ }^{17}$ More recently, two $T$ cell lines and two $T$ cell hybridomas reactive with HFPG were raised from arthritic Balb/c mice after immunisation with chondroitin sulphate depleted HFPG. One of the $T$ cell lines and the two $T$ cell hybridomas recognised homologous sequences in the $\mathrm{G} 1$ domain of adult human aggrecan and link protein, which suggests that link protein is a potential autoantigen. ${ }^{18}$ Furthermore, in the rat adjuvant arthritis model, ${ }^{19}$ arthritogenic $T$ cell clones have been developed which recognise an epitope on a mycobacterial heat shock protein (hsp65), having some homology with link protein. These clones are also capable 
of eliciting delayed type hypersensitivity responses to preparations of articular cartilage extracts rich in link protein.

Increased $T$ cell responses to type II collagen $^{2021}$ and cartilage proteoglycan ${ }^{22} 23$ have been described in some patients with RA, although other groups failed to detect antiproteoglycan responses. ${ }^{21}{ }^{24}$ Recently, we have shown that RA patients have increased $T$ cell proliferative responses to deglycosylated human articular cartilage aggrecan.$^{25} \mathrm{Here}$, we report the results of a survey of cellular immunity to human articular cartilage link protein, to bovine type II collagen, and to a synthetic peptide corresponding to the arthritogenic epitope in hsp65, ${ }^{19}$ in patients with inflammatory arthritis and normal age matched controls.

\section{Patients and methods}

PATIENTS AND CONTROLS

Two consultant rheumatologists collected samples from patients attending the hospital as outpatients or receiving inpatient treatment. All the patients had active definite or classical RA. ${ }^{26}$ The mean age of the 47 patients tested with link protein was 59.5 years (SD 13.2, range 29-79). Control subjects without arthritic symptoms were recruited from local voluntary associations and had a mean age of 50.2 years (SD 13.5, range 21-82). For tests involving subpopulations of each group, the subgroups were selected randomly with no age bias. Each patient or control provided samples of heparinised and clotted blood and, in addition, synovial fluid was aspirated from the knee joints of 17 patients as part of their medical treatment.

\section{ANTIGENS}

Link protein was purified as previously described. ${ }^{27}$ Briefly, macroscopically normal human articular cartilage obtained from patients who had undergone total hip or knee replacement was minced and extracted with $4 \mathrm{~mol} / \mathrm{l}$ guanidine hydrochloride ( $\mathrm{GuHCl})$. The extract was then fractionated by associative, followed by dissociative, caesium chloride density gradient centrifugation. The link protein rich A1D6 fraction was then mixed with AH-Sepharose 4B coupled to hyaluronic acid and the link protein eluted using $4 \mathrm{~mol} / \mathrm{l}$ $\mathrm{GuHCl}$. Link protein was dialysed extensively against $1 \mathrm{~mol} / 1$ sodium chloride, $10 \mathrm{mmol} / 1$ 3-(N-morpholino) propanesulphonic acid (MOPS), $\mathrm{pH} 7 \cdot 0$. In this buffer, link protein forms stable oligomers in solution. The link protein was further purified by fractionation on a Sephadex G-150 Superfine column in MOPS buffer and fractions were assessed for purity on sodium dodecyl sulphate-polyacrylamide gel electrophoresis 4-20\% gradient gels stained with Coomassie Brilliant Blue R-25028 followed by silver staining. The Novex Xcell electrophoresis system (Novex, San Diego, USA) was used to perform Western blotting of protein bands in unstained gels onto nitrocellulose. ${ }^{29}$ The blots were probed with the link protein specific monoclonal antibody 9/30/8A4 and the aggrecan G1 and G2 domain specific antibody 12/21/1C6 (Developmental Hybridoma Bank). Purified link protein was used in mononuclear cell proliferation assays after sterile filtration through a $0.2 \mu \mathrm{m}$ pore size membrane. Link protein solutions were stored at $4^{\circ} \mathrm{C}$ and the protein concentration was determined using the bicinchoninic assay (BCA) for protein (Pierce).

Because the link protein preparation contained MOPS, the effect of MOPS upon T cell proliferation was investigated. MOPS was not found to be generally inhibitory to mitogen (concanavalin A (con A)) or antigen (purified protein derivative (PPD) or tetanus toxin) driven proliferation at concentrations less than $300 \mu \mathrm{mol} / 1$ (data not shown). Nevertheless, those individuals (four of 96) with a high sensitivity to MOPS mediated inhibition, as demonstrated by a significantly reduced stimulation index in the presence of MOPS, were removed from the study.

Bovine nasal type II collagen was a kind gift of Dr S Ayad and purified Mycobacterium bovis derived hsp65 was a kind gift of Dr W Van Eden. A synthetic 17 amino acid peptide corresponding to hsp65 residues $180-196^{19}$ was the kind gift of Dr D B Young. PPD or tetanus toxin were used as control antigens and con $\mathrm{A}$ was used as a control mitogen.

MONONUCLEAR CELL PROLIFERATION ASSAY Serum was prepared from clotted blood and complement inactivated by heating at $56^{\circ} \mathrm{C}$ for 30 minutes. Mononuclear cells were purified from heparinised peripheral blood (PBMC) or synovial fluid (SFMC) by centrifugation on Lymphoprep (Nycomed). The mononuclear cells were washed twice with RPMI 1640 (Dutch modification), supplemented with $1 \% \mathrm{v} / \mathrm{v}$ penicillin/streptomycin (Sigma) and $2 \mathrm{mmol} / \mathrm{l}$ L-glutamine (Sigma). The cells were then plated at a density of $2 \times 10^{5}$ cells per well $(200 \mu \mathrm{l})$ in supplemented RPMI containing $10 \% \mathrm{v} / \mathrm{v}$ autologous complement inactivated serum in sextuplicate in 96 well flat bottomed plates, with or without the following antigens or mitogens: concanavalin A $1 \mu \mathrm{g} / \mathrm{ml}$, link protein $20 \mu \mathrm{g} / \mathrm{ml}$, hsp65 $20 \mu \mathrm{g} / \mathrm{ml}$, bovine nasal type II collagen $20 \mu \mathrm{g} / \mathrm{ml}, 17$ amino acid hsp65 peptide $1 \mu \mathrm{g} / \mathrm{ml}$, PPD $50 \mathrm{U} / \mathrm{ml}$, tetanus toxin $0.01 \%$. The concentration of link protein and hsp65 were selected after a pilot scale dose-response study (unpublished results). The cells were incubated for five days at $37^{\circ} \mathrm{C}$ in $5 \%$ carbon dioxide and then pulsed with ${ }^{3} \mathrm{H}$-thymidine $(1 \mathrm{mCi} /$ well; specific activity $2 \mathrm{Ci} / \mathrm{mmol}$ ). After six hours the cells were harvested onto glass fibre filter mats and the level of incorporation of thymidine determined by liquid scintillation counting. Lymphocyte responses were expressed as stimulation indices (SI), defined as the ratio of the level of incorporation of ${ }^{3} \mathrm{H}$-thymidine in mononuclear cells exposed to antigen to the level of incorporation in unstimulated cells (negative control). 
STATISTICAL METHODS

Two different criteria were used to compare $T$ cell responses with link protein in patients and controls. First, positive $T$ cell responses were defined arbitrarily as a significantly increased thymidine incorporation compared with zero addition controls $(p<0.05$ by the MannWhitney U test), where SI was at least $1 \cdot 5$. The proportion of individuals in each group showing positive responses were compared using Fischer's exact test. Second, by taking the natural logarithm of the SIs in the control population, it was possible to define a range of values which did not significantly differ from a normal distribution, and to calculate an upper limit for this range (defined as 2 SD above the mean of the transformed values). The number of patients and controls with SIs greater than this value were then compared. The SI of PBMC and SFMC (in those from whom synovial fluid could be obtained) were compared using the paired $t$ test.

\section{Results}

Enhanced $T$ cell proliferative responses to link protein, defined as an SI value $>1.50$, were given by the PBMC of $26 \%$ of the RA patients tested-a significantly greater proportion ( $p<0.05$ by Fischer's exact test) than in the non-arthritic control group, of whom fewer than $10 \%$ showed increased responses (table 1). Table 2 shows the range of stimulation indices in patients and controls. The distribution of the natural logarithm of SI values in normal controls did not vary substantially from normal $(\chi 2, p=0.409)$, with a mean of 0.08 (SD 0.42). An upper limit on the control reference range was set 2 SD above the mean, which corresponded to an SI value of 2.5 (95\% confidence interval $2 \cdot 1$ to $3 \cdot 2$ ). Only one of the SI values of the patient group and two of those from the controls fell outside the reference range.

In those 17 patients from whom synovial fluid was obtained, eight $(47 \%)$ had SI values

Table 1 Number of individuals in each group showing significantly (Mann-Whitney $U$, $p<0.05$ ) increased mononuclear cell proliferation (stimulation index $>1.5$ ) in response to each antigen, compared with negative control

\begin{tabular}{lllll}
\hline & \multicolumn{4}{l}{ Positive individuals (\%) } \\
\cline { 2 - 5 } & $\begin{array}{l}\text { Link } \\
\text { protein }\end{array}$ & $\begin{array}{l}\text { Bovine } \\
\text { collagen II }\end{array}$ & $\begin{array}{l}\text { Intact } \\
\text { hsp65 }\end{array}$ & $\begin{array}{l}\text { hsp65 } \\
180-196 \ddagger\end{array}$ \\
\hline RA PBMC & $12 / 46(26 \cdot 1)^{\star}$ & $1 / 13(7 \cdot 7)$ & $8 / 9(89 \cdot 9)$ & $0 / 13(0)$ \\
RA SFMC & $8 / 17(47 \cdot 1)^{\star}$ & $0 / 12(0)$ & $4 / 5(80)$ & $0 / 14(0)$ \\
Normal PBMC & $4 / 44(9 \cdot 1)$ & NT & $7 / 7(100)$ & NT \\
\hline
\end{tabular}

RA = Rheumatoid arthritis; PBMC, SFMC = peripheral blood and synovial fluid mononuclear cells, respectively. NT $=$ Not tested. ${ }^{\star}$ Significantly increased ratio of responders to nonresponders compared with normal PBMC ( $\mathrm{p}<0.02$ by Fischer's exact test). +Four of the 13 RA PBMC and five of the 12 RA SFMC tested were positive responders to link. FFour out of the 13 RA PBMC and six of the 14 RA SFMC tested were positive responders to link.

Table 2 Median value and range of stimulation indices in those individuals challenged with link protein, compared with negative control

\begin{tabular}{lll}
\hline & Median SI & Range \\
\hline RA patient PBMC $(n=46)$ & $1 \cdot 1$ & $0 \cdot 5-3 \cdot 1$ \\
RA patient SFMC $(n=17)$ & $1 \cdot 3$ & $0 \cdot 6-3 \cdot 1$ \\
Normal PBMC $(n=44)$ & $1 \cdot 1$ & $0 \cdot 5-3 \cdot 2$ \\
\hline
\end{tabular}

RA = rheumatoid arthritis; PBMC, SFMC = peripheral blood and synovial fluid mononuclear cells, respectively.
$>1.5$ when the SFMC were challenged with link protein. In 16 of the 17 patients, the proliferative responses of the SFMC and PBMC to link protein could be compared directly; no significant difference between the SI for PBMC and that for SFMC was found by the paired $t$ test.

PBMC and SFMC cells from responders and non-responders to link protein were tested for proliferative responses to type II collagen, but only one of the patients tested demonstrated a significant SI: this was with PBMC but not the SFMC of a patient unresponsive to link protein. Cells from both responders and non-responders were also challenged with the synthetic 17 amino acid peptide corresponding to hsp65 residues $180-196$. None of the patients tested (table 1) showed increased SI values, whereas a high proportion of RA patients (eight of nine) and non-arthritic controls (seven of seven) showed increased responses to intact hsp65.

Neither the frequency nor the magnitude of increased responses to link protein appeared to be correlated with the duration or severity of the disease, or to the age or gender of the patient. There was no significant difference in the response of patients and controls to mitogen or control antigen.

\section{Discussion}

We have previously found that antibodies to link protein were present in the serum of patients with RA, but not at significantly greater frequency or titre than in control individuals. $^{27}$ In the present study we have shown that a greater proportion of RA patients have peripheral blood derived $T$ cells reactive to link protein (defined as an SI of 1.5 or greater) than non-arthritic individuals. The frequency of such responses was greater still in synovial fluid derived T cells. However, as the SI values for PBMC for all but one of the patients fell within the control range, it was not posible to show a relationship between the magnitude of these responses and the presence of RA. It seems likely that sub-groups of both RA patients and controls show weak $T$-cell proliferative responses to link protein.

Evidence from adjuvant induced arthritis had led to the hypothesis that molecular mimicry between mycobacterial heat shock proteins and cartilage proteoglycan could lead to autoimmune responses and arthritis. ${ }^{19}{ }^{30} \mathrm{In}$ the adjuvant arthritis model, $\mathrm{T}$ cell cloning gave rise to both arthritogenic (A2b) and protective (A2c) $T$ cell clones which recognised the same epitope (AA 180-188) on M.tuberculosis hsp65. This peptide has $44 \%$ homology with rat chondrosarcoma link protein and $33 \%$ with human cartilage link protein. Transfer of the arthritogenic clone $A 2 b$ to naive animals gave rise to enhanced delayed-type hypersensitivity responses to preparations of cartilage proteoglycans rich in aggrecan and link protein. In this study, although we found a high percentage of patients and controls responsive to hsp65 (which is not surprising in light of widespread 
immunisation with M.tuberculosis), no reactivity to a 17 amino acid synthetic peptide incorporating the sequence AA 180-188 was observed, regardless of whether patients showed reactivity to link protein or to intact M.bovis hsp65. We must conclude that in the patients tested this epitope is not immunodominant, and the responses to link protein are not attributable to cross reactivity with it. In a study analysing the pattern of responses of $\mathrm{T}$ cells reactive with $M$.tuberculosis in the synovial fluid of RA patients, ${ }^{31} 12$ different antigenic specificities were seen in a panel of $15 \mathrm{~T}$ cell clones purified from four patients. Thus it seems unlikely that, in RA, $T$ cell responses in the joint are directed principally against those sequences in autoantigens homologous with mycobacterial proteins.

Link protein shares significant homology with the G1 and G2 domains of aggrecan, ${ }^{4}$ and $T$ cell responses to aggrecan in the murine HFPG induced model of arthritis have been investigated. From the results of one study it has been suggested that the predominant $T$ cell epitopes on aggrecan may be in the chondroitin sulphate attachment region; ${ }^{32}$ however, in another study $\mathrm{T}$ cell lines and hybridomas have been shown to cross react with link protein. ${ }^{18}$ The responses to link protein reported here are somewhat different from RA patient and normal control $\mathrm{T}$ cell responses to deglycosylated aggrecan. ${ }^{25}$ First, RA patients showed a greater incidence of $\mathrm{T}$ cell proliferative responses to aggrecan than to link protein. Second, compared with those of responding $R A$ patients, the stimulation indices given by responsive normal controls were similar against link protein, but generally lower against aggrecan.

Cellular immunity to link protein may play a role in the initiation or maintenance of the chronic inflammatory response in at least some RA patients, though it is difficult to distinguish if such immune responses are causal or a result of the destructive process. Articular cartilage is believed to be an immunologically privileged site and the continual, often aggressive erosion of cartilage in patients with RA may release novel matrix epitopes able to elicit secondary immune responses to a wide range of matrix components. It has been shown that the level of release of hyaluronan binding region into synovial fluid is much greater in RA patients with advanced cartilage degeneration than in those with little or no cartilage damage.$^{33}$ It is also possible that such epitopes are released during cartilage damage unrelated to the presence of inflammatory arthritis, including that caused by degenerative arthritis or by trauma, which may explain the presence of $T$ cells responsive to link protein in the control population. Fragments from proteoglycans and associated matrix components may be cross reactive with pathological organisms, or altered antigen processing may result in the presentation of cryptic epitopes to $T$ cells, as has been observed in the Balb/c mouse model of proteoglycan induced arthritis. ${ }^{34}$ Further work on the processing of proteoglycans by cells from RA patients and normal individuals and mapping $\mathrm{T}$ cell epitopes on these antigens is needed to determine the relevance of our findings.

This study was funded by the Arthritis and Rheumatism Council and the research panel of the Institute of Orthopaedics, Oswestry.

The authors wish to acknowledge $\operatorname{Dr} \mathrm{R}$ C Butler and Dr J J Dixey, both for their cooperation in obtaining clinical specimens, and for their advice and comments.

1 Firestein G S, Zvaifler N J. How important are T-cells in chronic rheumatoid synovitis. Arthritis Rheum 1990; 33: 768-73.

2 Panayi G S, Lanchbury J S, Kingsley G H. The importance of the T-cell in initiating and maintaining the chronic synovitis of rheumatoid arthritis. Arthritis Rheum 1992; 35: 729-35.

3 Rosenberg L C, Buckwater J A. Cartilage proteoglycans. In: Keuttner K, Schleyerbach R, Hascall V C, eds. Articular cartilage biochemistry. Workshop conference Hoechst-Werk

4 Neame P J, Barry F P. The link proteins. Experientia 1993; 49: 393-402

5 Hardingham T, Bayliss M. Proteoglycans of articular cartilage: changes in aging and in joint disease. Semin Arthritis Rheum 1990; 20(suppl 1): 12-33.

6 Trentham D E, Townes A S, Kang A H. Autoimmunity to type II collagen: an experimental model of arthritis. $\mathcal{F}$ Exp Med 1977; 146: 857-68.

7 Courtenay J S, Dallman M J, Dayan A D, Martin A, Mosedale B. Immunisation against heterologous type II collagen induces arthritis in mice. Nature 1980; 283: 666-8.

8 Trentham D E. Collagen arthritis as a relevant model for rheumatoid arthritis. Arthritis Rheum 1982; 25: 911-6.

9 Holmdahl R, Jansson L, Larsson E, Rubin K, Klareskog L. Homologous type II collagen induces chronic and progressive arthritis in mice. Arthritis Rheum 1986; 29: 106-13.

10 Boissier M-C, Feng X-Z, Carlioz A, Roudier R, Fournier C. Experimental autoimmune arthritis in mice. I. Homologous type II collagen is responsible for self perpetuating chronic polyarthritis. Ann Rheum Dis 1987; 46: 691-700

11 Boissier M-C, Chiocchia G, Ronziere M C, Herbage D, Fournier C. Arthritogenicity of minor collagens (Type IX and XI) in mice Arthritis Rheum 1990; 33: $1-8$.

12 Glant T T, Olah I. Experimental arthritis produced by proteoglycan antigens in rabbits. Scand $f$ Rheumatol 1980; proteoglycan

13 Glant $T T$. Induction of cartilage degradation in experimental arthritis produced by allogeneic and xenogeneic proteoglycan antigens. Connect Tissue Res 1982; 9: $137-44$

4 Glant T T, Mikecz K, Arzouminanian A, Poole A R. Proteoglycan-induced arthritis in Balb/c mice. Arthritis Rheum 1987; 30: 201-12.

15 Mikecz K, Glant T T, Poole A R. Immunity to cartilage proteoglycans in Balb/c mice with progressive polyarthritis and ankylosing spondylitis induced by injection of human cartilage proteoglycan. Arthritis Rheum 1987; 30: 306-18.

16 Trentham D E, Dynesius R A, David J R. Passive transfer by cells of type II collagen-induced arthritis in rats. $\mathcal{f}$ Clin Invest 1978; 62: 359-66.

7 Mikecz K, Glant T T, Buzas E, Poole A R. Proteoglycaninduced polyarthritis and spondylitis adoptively transferred to naive (non-immunised) $\mathrm{Balb} / \mathrm{c}$ mice. Arthritis Rheum 1990; 33: 866-76.

18 Leroux J-Y, Poole A R, Webber C, et al. Characterisation of proteoglycan-reactive $\mathrm{T}$-cell lines and hybridomas from mice with proteoglycan-induced arthritis. 7 Immunol 1992; 148: 2090-6.

19 van Eden W. Heat-shock proteins in autoimmune arthritis: A critical contribution based on the adjuvant arthritis A critical contribution based on

20 Trentham D E, Dynesius R A, Rocklin R E, David J R. Cellular sensitivity to collagen in rheumatoid arthritis. New Engl f Med 1978; 299: 327-32.

21 Golds E E, Stephen I B, Esdaile J M, Strawczynski H, Poole A R. Lymphocyte transformation to connective tissue antigens in adult and juvenile rheumatoid arthritis, osteoarthritis, ankylosing spondylitis, systemic lupus erythematosus and a nonarthritic control population. Cell Immunol 1983; 82: 196-209.

22 Nozoe $M$, Dennis M V, Herman J H. Modulation of human lymphocyte responses by cartilage proteoglycan and glycosaminoglycans-A comparison between normal glycosaminoglycans-A comparison between normal subjects and patients with rheumatoid

23 Glant T T, Csongor J, Szucs T. Immunopathologic role of proteoglycan antigen in rheumatoid joint disease. Scand f Immunol 1980; 11: 247-52.

24 Sigal L H, Johnston S L, Phillips P E. Cellular immune responses to cartilage components in rheumatoid arthritis and osteoarthritis: a revien

25 Goodstone N J. Cellular responses to components of the extracellular matrix of human articular cartilage in 
patients with rheumatoid arthritis. [PhD Thesis] Manchester: University of Manchester, 1994.

26 Arnett F C, Edworthy S M, Bloch D A, et al. The American Rheumatism Association 1987 revised criteria for the classification of rheumatoid arthritis Arthritis Rheum 1988; 31: 315-23.

27 Austin Ashton B A. Humoral immunity to link protein in patients with inflammatory joint disease, osteoarthritis, and in with inflammatory joint disease, osteoarthritis, and in 8 Laemmli U K. Cleavage of structural proteins during the assembly of the head of bacteriophage T4. Nature 1970 227: 680-5.

29 Towbin H, Staehelin T, Gordon J. Electrophoretic transfe of proteins from polyacrylamide gels to nitrocellulose sheets: Procedure and some applications. Proc Natl Acad Sci USA 1979; 76: 4350-4.
30 van Eden W, Thole J E R, van der See R, et al. Cloning of the mycobacterial epitope recognised by $T$-lymphocytes in adjuvant arthritis. Nature 1988; 331: 171-3.

31 Res P C, Orsini D L, Van Laar J M, Janson J M, AbouZeid C, De Vries $\mathbf{R}$ R. Diversity in antigen recognition by Mycobacterium tuberculosis-reactive $\mathrm{T}$-cell clones from the synovial fluid of rheumatoid arthritis patients. Eur f Immunol 1991; 21: 1297-1302.

32 Mai A, Walcz E Hovarth P, Glant T T Expression of $c D N A$ clones encoding core protein domains of mouse aggrecan. clones encoding core protein domains of mouse aggrecan.

33 Saxne T, Heinegard $D$. Synovial fluid analysis of two groups of proteoglycan epitopes distinguishes early and late

34 Goodacre J A, Middleton S, Lynn S, Ross D A, Pearson J. Human cartilage aggrecan CS1 region contains cryptic T-cell recognition sites. Immunology 1993; 78: 586-91. 